\title{
Spatial Analysis of Risk Factors of Potable Water and The Efficiency of HIV/AIDS in Ekiti State, Nigeria
}

\author{
Folorunso Owoola, Wole W. Adebayo, and Kayode O. Olowe
}

\begin{abstract}
Human immunodeficiency virus (HIV) and Acquired immunodeficiency syndrome (AIDS) have been a major problem around the world, and various control have been put in place to tame this potentially life-threatening virus. The research aims to expose the relationship between HIV/AIDS and potable water. However, it is generally believed that the virus cannot be contacted through water, but the interface between HIV/AIDS may likely be influenced through scarcity of water. The data for this research was collected through administration of questionnaire to people leaving with HIV/AIDS (PLWHA) at major health institutions in the three senatorial districts in Ekiti state. The data collected were analyzed using statistical tools and the results show that $44.5 \%$ of the respondents believed that water availability can reduce the spread of HIV/AIDS infection around the study area. $84.5 \%$ of the respondents had an increased need of water after HIV infections. While $\mathbf{9 2 . 7 \%}$ of the respondents agreed HIV positive people have increased need for better hygiene and sanitation. The study discovers that water, sanitation, hygiene and population are agents determining the spread of HIV/AIDS in the environment. Thus, planning and proper spread of infrastructure that support supply of potable water will reduce and control the virus.
\end{abstract}

Keywords - HIV/AIDS, Potable-water, Sanitation, Hygiene

\section{INTRODUCTION}

Human Immunodeficiency Virus/Acquired Immune Deficiency Syndrome (HIV/AIDS) remain one of the most challenging emerging infectious diseases in the last decade and it continues to create health and socio-economic challenges in the world at large [1]. Environmental issues such as tropical infections, poor living conditions and limited access to safe drinking water and sanitation facilities expose persons with HIV to increase risks of opportunistic infections, including diarrhea [2-3]. Two decades have rolled by, since the first case of AIDS was diagnosed in Nigeria in. Since that time, many individuals, families, communities and businesses in Nigeria have felt the devastation of the epidemic. Since the first case was recorded, the HIV zero-prevalence rate has been increasing gradually, moving from a national prevalence of $1.8 \%$ in $1991,3.8 \%$ in 1993 , to $4.5 \%$ in $1995 / 96,5.4 \%$ in $1999,5.8 \%$ in $2001,5.0 \%$ in $2003,4.4 \%$ in 2005, and $4.6 \%$ in 2008 [4]. According to the 2008 sentinel survey, there are 2.95 million Nigerians (male: 1.23million; female: 1.72million) estimated to be living with HIV with new infections in 2008 at 380,000 (adult: 223,000; children: 57,000). While in 2013, 3.4million Nigerians were living with HIV/AIDS, making Nigeria the second largest country where the disease has afflicted so many people (Idoko, 2013). The annual HIV positive birth is estimated at 56,681 while the cumulative AIDS death since 1986 is 2.99 million (male: 1.38 million; female: 1.61million) [5]. In 2008 the annual AIDS death is 280,000 (male: 123,000; female: 157,000). The total number of People Living With HIV (PLWH) requiring AntiRetroviral Therapy (ART) is 833,000 (adult: 740,000; children: 92,000) while the total AIDS orphaned stands at 2.23million [4].

At a glance, the issue of HIV/AIDS and water supply and sanitation would appear to bear very little relation to each other. HIV/AIDS is a global-scale pandemic that is transmitted between people primarily through sexual contact, while water is a renewable natural resource of which the availability depends on a variety of geographic and climatic factors. Closer inspection of the features that characterize the spread of HIV/AIDS and its implications for individuals, communities and societies reveal several significant linkages with water as HIV/AIDS, water supply, and sanitation reflect some of the often-unanticipated effects of the pandemic on society. However very few research efforts have been geared towards this kind of relation in Africa. Water is the principal constituent of all living organism, human, animal and plants, it is most basic of natural resources [6]. It is one of the elemental forces of nature that is indispensable to man. Water is central to human existence and an essential life-support resource for both for the rich and the poor [7].

Nevertheless, for water to serve its useful purpose, it must be hygienically purified. People living with HIV and AIDS (PLWHA) suffer particularly from the health and social impacts of inadequate infrastructure as related to potable water and sanitation as their need for clean water, sanitation and hygiene practices increases as they struggle to protect themselves from infection, or cope with the disease symptoms. PLWHAs' experiences of stigmatization and discrimination have also been common at various levels household, community and by service providers - with regards to both water and sanitation access. While access to water and sanitation services is not just a basic need but a human right for everyone regardless of HIV/AIDS status, it 
is particularly important for the maintenance of life in PLWHA. Despite the importance of water and sanitation, majority of people in the world have no access to this essential commodity as pointed out by [8]. Though there has been a significant development in the area of water and sanitation in the developed countries but developing countries are still faced with the challenge. The number of people without access to safe water dropped during 19901994 by around 470 million. However, people without safe water increased in Africa, Latin America and the Caribbean. In rural areas, majority of people have access only to standpipes and hand-pumps. However, the supply is often intermittent, people queue for long periods and most often the hand pumps are poorly maintained. Nigeria is not exempted from the menace of inadequate safe water and basic sanitation facilities. Many Nigerians have no access to this basic need and people in Ekiti State are equally affected [9].

The stigmatization, associated with HIV/AIDS might make PLWHA find it more difficult psychologically, socially and emotionally in the community and even to express their challenges as regards their accessibility to water and other basic infrastructural facilities. This study therefore aims to analyze the availability of safe water, access to potable water, proximity to safe water, effect of safe water on the PLWHA in Ekiti State. Further, the effect on the spread of HIV/AIDS, sanitation and hygiene improvement activities that can be incorporated into HIV/AIDS programs were considered in the study. After all, the global statistics are shocking: 884 million people lack access to safe drinking water; 2.6 billion people do not have access to basic sanitation; 1.5 million children under five die each year from water and sanitation-related diseases[10-11]. With individual health and hygiene being largely dependent on availability of potable drinking water and proper sanitation, consumption of unsafe drinking water; improper disposal of human excreta and poor sanitation are attributed to high infant mortality rate and incidence of diseases, such as malaria and diarrhea. This study will also uncover the level of awareness in relation to the use of potable water and sanitation and its effect on HIV/AIDS spread and recovery of patience, particularly opportunistic and socialistic victims in the environment.

\section{Methodology}

This section describes the method employed in this research through the process of obtaining data directly from the study area and the analysis of current water consumptions around the study area. The study was conducted in Ekiti State which is made of three Senatorial Districts. Purposive sampling method was used to select the hospitals of interest which have the necessary facilities. For this reason, the study was conducted at the Federal Medical
Centre, Ido- Ekiti; The University Teaching Hospital, AdoEkiti; State Specialist Hospital, Ikere- Ekiti; State Specialist Hospital, Ikole-Ekiti, State Specialist Hospital, Ijero-Ekiti and General Hospital Omuo-Ekiti.. The first of the six is a federal government owned health institution while the other five are owned by the state government. The choice of the hospitals was premised on geographical representation of population and quality health facility provisions with reference to the three senatorial districts of the state. These hospitals are well staffed and well equipped. They also provide HIV/AIDS related services (VCT, ART and/or Intravenous Drug Use (IDU) rehabilitation and other social and support services. The study population involves people affected by HIV/AIDS who visit the health institutions for services. Since infected people cannot be identified without medical aids, so the people who never visited hospitals were not involved in the collection of the data.

\section{A. Study Design, Techniques and Tools}

The sampling frame for this study are PLWHA that attend regular clinic at their respective designated places and the location used for the sampling were Ekiti South (Ikere and Omuo), Ekiti Central (Ado and Ijero) and Ekiti North (Ido and Ikole) Senatorial Districts. From this sampling frame 110 respondents within these districts were interviewed, while particular attention was paid to major Health Institutions of those senatorial districts. A total of 110 copies of questionnaire were administered. The respondents were selected using purposive sampling techniques. The research used both primary and secondary data. Primary data was collected through structured interviews using close-ended questionnaires with people living with HIV/AIDS. One hundred and ten (110) people, comprising 42 males and 68 females, living with HIV/AIDS who visited the service sites during the period of data collection were asked for willingness to participate in the survey. Necessary steps were taken to ensure the rights, anonymity and confidentiality of the participants during the whole study. The data collection tools were prepared in English and all the questions were pre-tested with representative participants prior to the actual field survey. The data were analyzed, the secondary data was collected from the treatment centers, which includes treatment data of PLWHA.

To evaluate the challenges of PLWHA, the Ordinary Least Squares (OLS) estimation technique was adopted to measure the parameters of the specified relationship between AIDS which was the dependent variable and water supply, sanitation, hygiene needs and population are the independent variables. The following functional relationships were specified: 
(1)

Where: AIDS is Acquired Immune Deficiency Syndrome, PWS represents Potable Water Supply, SNT represents Sanitation, HGN represents Hygiene, POP is Population, and $\varepsilon$ is error term. For the purpose of estimation, we reexpress the functional relationship in mathematical form as follows in equation (2)

$$
A I D S=\alpha+\beta P W S+\psi S N T+\mu H G N+\Pi P O P+\xi
$$

Where: $\alpha$ is the constant term (or intercept), $\beta, ¥, \mu, \pi$ are the coefficient of water supply, sanitation, hygiene and population respectively, while $\varepsilon$ is the error term/stochastic variable. The stochastic variable represents all other variables that affect AIDS but which the impacts are negligible. It is expected that $\alpha \geq 0, \beta<0, ¥<0, \mu<0, \pi>$ 0 .

\section{RESUltS ANALYSIS AND DISCUSSION}

In this section, data collected from field survey were presented and analyzed through tables, charts, correlation and regression analysis, with inferences drawn from analyses of the data.

\section{A. Demographic Characteristics of the Respondents}

Figure 1 shows that the largest proportion of respondents within the age group is between 31-50yrs (51.8\%) and 19-
30 years $(30.9 \%)$. This is an expected confirmation of the high prevalence of HIV/AIDS among the sexually active groups. It was observed from Table 1 that males represented $38.2 \%$ of total respondents in the survey far less than the female proportion of $61.8 \%$ inferring that HIV/AIDS is more prevalent among the females than the males. This suggests the possibility of the exchange of water for sex and rape which can occur in the process of searching for water from streams and other locations which is a function primarily undertaken by the females. Table 2 shows that out of the total respondents in the survey, $53.6 \%$ were single, $36.4 \%$ were married, and $6.4 \%$ were widows/widowers, while $3.6 \%$ are divorced or separated. This reflects that HIV/AIDS is higher among singles than the married. The percentage of prevalence among the singles $(53.6 \%)$ was even higher than the sum of the prevalence among the married, divorced and the widow/widower put together (46.4\%).

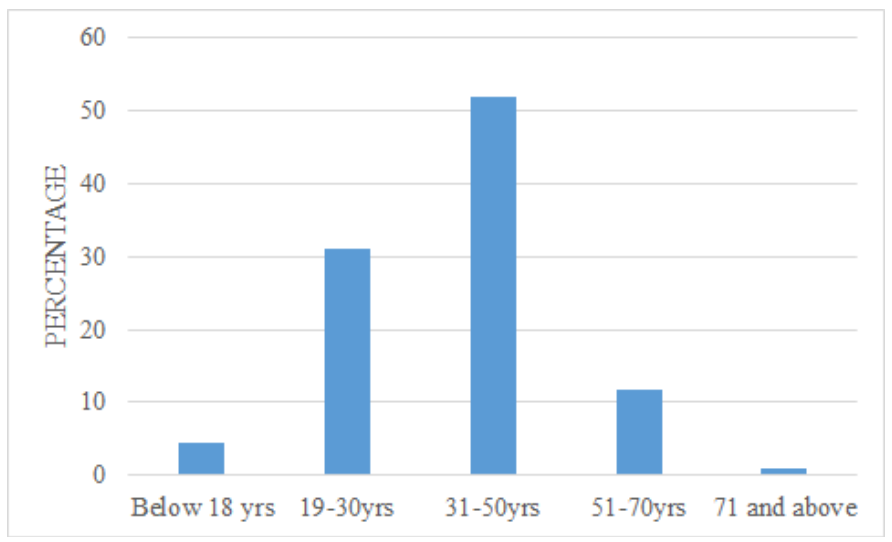

Figure 1: Age of Respondents

Table 1: Gender of Respondents

\begin{tabular}{llll}
\hline Gender & Frequency & Percentage & Cumulative Percentage \\
\hline Male & 42 & 38.2 & 38.2 \\
Female & 68 & 61.8 & 100.0 \\
Total & 110 & 100.0 & \\
\hline
\end{tabular}

Table 2: Marital Status of Respondents

\begin{tabular}{llll}
\hline Marital status & Frequency & Percentage & Cumulative Percentage \\
\hline Single & 59 & 53.6 & 53.6 \\
Married & 40 & 36.4 & 90.0 \\
Widow/Widower & 7 & 6.4 & 96.4 \\
Divorced/Separated & 4 & 3.6 & 100.0 \\
Total & 110 & 100.0 & \\
\hline
\end{tabular}




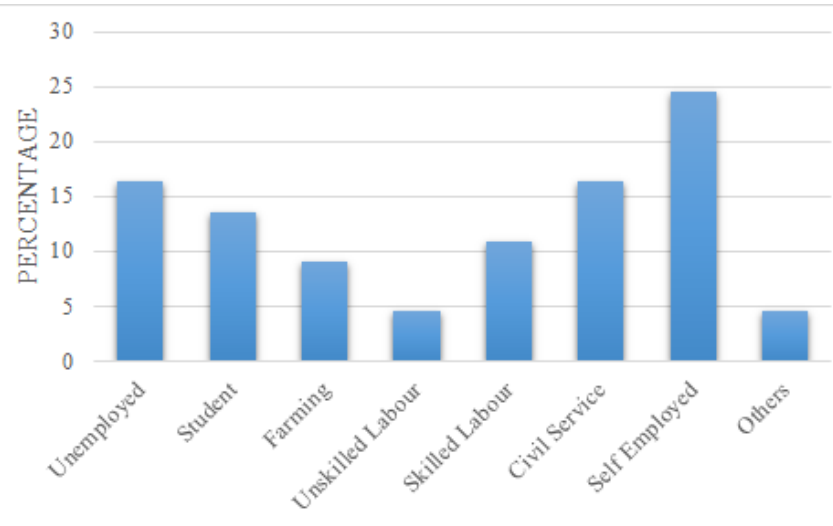

Figure 2: Occupation of Respondents

The occupational distribution of respondents from Figure 2 shows that $24.5 \%$ were within the self-employed group while unskilled labour and others had a prevalence rate of $4.5 \%$. Generally, the spread was fairly even given that there were various factors contributing to the spread of HIV/AIDS among the various occupational distributions as grouped in the figure.

\section{B. Sources of Water}

To assess the availability of potable water, and its contribution to the spread of HIV/AIDS in Ekiti State, the various sources of water available in the study area were determined. The question "how do you get your water?" was directed at the respondents, and the various sources of water captured by the questionnaire were well, borehole, pipeborne water, streams, and other sources. Table 3 presented the various sources of water available to people living with HIV/AIDS in Ekiti State in each of the Local Government Areas covered by the study. Table 3 shows that $42.7 \%$ of the people living with HIV/AIDS in Ekiti State sourced their water from wells, $23.6 \%$ from boreholes, and $30.9 \%$ have access to pipe-borne water, $1.8 \%$ get water from streams and $0.9 \%$ from other sources. During the dry season, $46.4 \%$ used to buy water, $14.5 \%$ get water from streams, $19.1 \%$ had access to pipe- borne water and $20 \%$ got water from others sources. This limited access of people to water reflected great vulnerability to a number of attendant risks, which are likely to include rape and exchange of water for sex, among others, and thus contributing to the incidence of HIV/AIDS. To assess the contribution of the various sources of potable water to the spread of HIV/AIDS in Ekiti State, Table 4 was presented reflecting the opinions of the respondents on water and HIV/AIDS. The result indicates that $44.5 \%$ of the respondents thought that water availability can reduce the spread of HIV/AIDS infection, while $55.5 \%$ on the other hand, and believes that water availability cannot reduce the spread of HIV/AIDS.

Table 3: Sources of Water

\begin{tabular}{cllll} 
& & Frequency & Percentage & Cumulative Percentage \\
\hline Water sources & Well & 47 & 42.7 & 42.7 \\
& Borehole & 26 & 23.6 & 66.4 \\
& pipe-borne water & 34 & 30.9 & 97.3 \\
& Streams & 2 & 1.8 & 99.1 \\
& Others & 1 & .9 & 100.0 \\
& Total & 110 & 100 & 46.4 \\
Water sources during dry & Buying & 51 & 46.4 & 60.9 \\
season & Streams & 16 & 14.5 & 80.0 \\
& pipe borne water & 21 & 19.1 & 100.0 \\
\hline
\end{tabular}

Table 4: Can sufficient potable water reduce the spread of HIV/AIDS

\begin{tabular}{clll}
\hline & Frequency & Percentage & Cumulative Percentage \\
\hline Yes & 49 & 44.5 & 44.5 \\
No & 61 & 55.5 & 100.0 \\
Total & 110 & 100.0 & \\
\hline
\end{tabular}


Table 5: The risk involve in search for water by HIV/AIDS patients

\begin{tabular}{|c|c|c|c|c|}
\hline & & Frequency & Percentage & Cumulative Percentage \\
\hline \multirow{3}{*}{$\begin{array}{lrr}\text { Can } & \text { water scarcity } \\
\text { cause } & \text { opportunistic } \\
\text { infection? } & & \end{array}$} & Yes & 44 & 40.0 & 40.0 \\
\hline & No & 66 & 60.0 & 100.0 \\
\hline & Total & 110 & 100 & \\
\hline \multirow{3}{*}{$\begin{array}{l}\begin{array}{l}\text { Have you } \\
\text { heen }\end{array} \text { or } \\
\text { victim? }\end{array}$} & Yes & 47 & 42.7 & 42.7 \\
\hline & No & 63 & 57.3 & 100.0 \\
\hline & Total & 110 & 100 & \\
\hline
\end{tabular}

To investigate the risk involved in search for water in Ekiti State, the result of the analysis was presented in Table 5. The risks involved in the search for water by HIV/AIDS patients in Ekiti State shows that about $40 \%$ of the respondents believes that water scarcity can cause opportunistic transmission and infection through rape or exchange of sex for water. $42.7 \%$ of the respondents have actually seen victims who had been raped or who had exchanged sex for water. The following are the risks and findings from the survey: A reasonable percentage of the respondents were females (61.8), single (53.6), unemployed (16.4) and lived below an income level of N10, 000 (30 dollars), and therefore, do not have access to a potable water source. Further, a reasonable percentage of the respondents sourced their water from well $(42.7 \%)$, thereby exposing them to high risk of infection -such as diarrhea, which possibly slow down the recovery and fasten the breakdown between the interfaces.

The prevailing knowledge, opinions, and practices of Water, Sanitation and Hygiene (WASH) amongst people living with HIV/AIDS in Ekiti State were also considered in this study. $92.7 \%$ of the respondents agreed that HIV positive people have increased need for better hygiene. $53.6 \%$ said the increased need for better hygiene was to prevent illness, $44.5 \%$ says the increased need for better hygiene is to slow down the interface of HIV/AIDS by preventing infections. About $66.4 \%$ of the respondents washed their hands before eating food, $14.5 \%$ washed their hand after food, while $11.8 \%$ washed their hands after going to the toilet. Only about $2.7 \%$ washed their hands after handling dust or dirt. $87.3 \%$ of the respondents had their bath every day, $10.9 \%$ bathed every alternate day, while only $1.8 \%$ bathed only once in a week, or less. Furthermore, $78.2 \%$ of the respondents brushed their teeth only once in day.

The experiences of people living with HIV/AIDS with regards to their access to WASH and factors associated with it in Ekiti State were analyzed. $20 \%$ of the respondents had no access to toilet facilities, $17.3 \%$ of them made use of the bush or field as latrine. The toilet facilities available to the rest $77.3 \%$ were being shared by 2 to 5 people per toilet facility or more. About $68.2 \%$ of the respondents had received hygiene related training, while only $31.8 \%$ said they had not had any related hygiene training. Those who had received hygiene related training got their training from support groups, $24.5 \%$ got their training from hospitals. The views of people living with HIV/AIDS on WASH and its link to their social lives and health in Ekiti State were discussed. $12.7 \%$ of the respondents said they suffered discrimination in the use of toilet facilities by family members. $25.5 \%$ of the respondents had been discriminated against by their service providers due to their HIV status. About $26.4 \%$ of the respondents had been deprived of their access to water at one time or the other by members of the community, and even some, by their own family members. The result further showed that this discrimination still happens. $32.7 \%$ respondents had been refused the use of toilet facilities by some family members and $63.7 \%$ from other members in the community. This revealed that there is lack of adequate orientation and enlightenment for people on the issue of HIV/AIDS.

The water, sanitation and hygiene practices (hand washing, treatment, and safe storage of water and sanitation/faeces management) and the perception of health risks which impact negatively on people living with HIV/AIDS in Ekiti State were examined. The result of the analysis indicated that $80.9 \%$ saw changes in their health status, about $86.4 \%$ of the respondents said improved supply of potable water can reduce the level of sickness. Also, domestic water use was observed to improve the health status of those living with HIV/AIDS. $41.8 \%$ of the respondents observed increased need for defecation after becoming HIV positive, and $31.8 \%$ said they have suffered from water borne diseases. To prevent diarrhea, the result indicates that drinking safe water, maintaining good hygiene, and eating good food were the ways HIV people can prevent diarrhea. It also shows that there is no public 
enlightenment/orientation and correct awareness to perfectly educate the community to avoid undue discrimination.

\section{Regression Analysis}

In evaluating the short term and long term effects of WASH on HIV/AIDS patients and its spread in Ekiti State, we adopted the regression estimation technique to measure the parameters of the relationship between AIDS - which is the dependent variable; water supply, sanitation, hygiene needs and population - the independent variables, as specified in equation (1). The result of the regression analysis table is presented in Table 6. The short-term and long-term effects of WASH on the spread of HIV/AIDS in Ekiti State were determined by the significance of each of the variables in the analysis.

Table 6: Result of the Regression Analysis

\begin{tabular}{lllll}
\hline Variables & B & Standard Error & T & Significance \\
\hline Constant $(\alpha)$ & -76.600 & 28.611 & -2.677 & 0.037 \\
sanitation $(\sigma)$ & -1.828 & 5.038 & -0.363 & 0.729 \\
Hygiene $(\mu)$ & -1.858 & 17.396 & -0.107 & 0.918 \\
portable water $(\beta)$ & -0.024 & 0.008 & -3.076 & 0.037 \\
Population $(\pi)$ & 0.001 & 0.000 & 3.332 & 0.009 \\
\hline
\end{tabular}

The result of the analysis indicates that sanitation had a negative relationship with HIV/AIDS in the three senatorial districts in Ekiti State, which implied that an increase in sanitation would lead to a reduction in the spread of HIV/AIDS, and since $\mathrm{p}<0.05$ in the three senatorial districts, it was inferred that sanitation was a significant determinant of HIV/AIDS in Ekiti State. In the same vein, hygiene had a negative relationship with the spread of HIV/AIDS in all the three senatorial districts in Ekiti State. The result of the analysis indicated that at $\mathrm{p}<0.05$, potable water supply has a negative relationship with HIV/AIDS. This implied that, potable water supply had the right sign, thus confirming the negative relationship between Potable Water Supply and HIV/AIDS. This implied that an increase in the provision and availability of people to water or availability of water reduced the spread of HIV/AIDS. Population, which measures the total number of people residing in the study area, was found to have a positive relationship with the spread of HIV/AIDS. The finding, with respect to population was in line with the theoretical provision. Increase in population will lead to an increase in the spread of HIV/AIDS. At $\mathrm{p}=0.05$, that is, at $5 \%$ level of significance, the result indicated that population was significant, therefore, contributing positively to increase in the spread of HIV/AIDS. Potable water supply had been identified as the variable of interest. Our findings indicated that potable water supply has been inadequate in most part of Ekiti State, even in the State Capital, Ado-Ekiti. Therefore, it can be concluded that the inadequate water supply could have exposed the people to risks, such as rape, or the exchange of sex for water, thereby contributing positively to the spread of HIV/AIDS. From Table 3, we discovered that well water was the major source of water to the majority of the respondents, thereby, affirming our finding that inadequate potable water supply had contributed to the spread of HIV/AIDS in Ekiti State and possibly worsened their health status and condition by influencing the interface between HIV and AID.
Based on the result from Table 7, the Regression indicates that the Central Senatorial District Sanitation (SNT) was 87.4 which implied that Sanitation did not support HIV/AIDS by 87.4 increases in Sanitation if other variables were held constant. Hygiene (HGN) was -454.9 which implied that hygiene on the same HIV/AIDS, if other factors (variables) were held constant, hygiene will decrease by 454.9 per unit decrease in the HIV/AIDS patient. While Potable water supply (PWS) was -14.2 implied that Potable water supply did not support HIV/AIDS by 14.2 increases in Potable water supply if other variables were held constant. In South Senatorial District Sanitation (SNT) was -86.6 which implied that Sanitation did not support HIV/AIDS by 86.6 increases in Sanitation if other variables were held constant. Hygiene (HGN) was -454.3 which implied that hygiene on the same HIV/AIDS, if other factors (variables) were held constant, hygiene will decrease by 454.3 per unit decrease in the HIV/AIDS patient. While Potable water supply (PWS) was -3.4 implied that Potable water supply did not support HIV/AIDS by 3.4 increases in Potable water supply if other variables were held constant. In North Senatorial District Sanitation (SNT) was -87.3 which implied that Sanitation did not support HIV/AIDS by 87.3 increases in Sanitation if other variables were held constant. Hygiene (HGN) was -454.9 which implied that hygiene on the same HIV/AIDS, if other factors (variables) were held constant, hygiene will decrease by 454.9 per unit decrease in the HIV/AIDS patient. While Potable water supply (PWS) was -3.0 implied that Potable water supply did not support HIV/AIDS by 3.0 increases in Potable water supply if other variables were held constant.

Man, as host, has directly influenced the healthiness of the environment by the significant role he plays in determining the availability and quality of water for his use and vice versa, while the quality of water determines the overall quality of the environment including the health of man. Water plays a significant role in determining the healthiness of man and the spread of HIV/AIDS like many other 
epidemiology occurrence and incidence. The regression results confirmed affirmatively the direct links of man as host with water as agent and the environment in which man lives. The environment refers to ranges from facilities available, population, infrastructures, etc. This explanation can also be extended to the remaining variables in the model. Sanitation, hygiene, and population were also agents determining the spread of HIV/AIDS in the environment.

Table 7: Result of the Regression Analysis in Senatorial Districts

\begin{tabular}{|c|c|c|c|c|c|}
\hline Senatorial Districts & Variables & $\mathrm{B}$ & Std. Error & $\mathrm{T}$ & Sig. \\
\hline \multirow[t]{5}{*}{ CENTRAL (C) } & Constant & -20.803 & 26.974 & -.771 & .442 \\
\hline & hand wash & -.874 & .874 & -.999 & .320 \\
\hline & Hygiene & -4.549 & 2.331 & -1.952 & .054 \\
\hline & $\begin{array}{l}\text { portable } \\
\text { water }\end{array}$ & .031 & .003 & 11.216 & .000 \\
\hline & Population & $6.552 \mathrm{E}-05$ & .000 & 1.711 & .090 \\
\hline \multirow[t]{5}{*}{ SOUTH (S) } & Constant & -10.272 & 23.700 & -.433 & .666 \\
\hline & hand wash & -.866 & .877 & -.987 & .326 \\
\hline & Hygiene & -4.543 & 2.338 & -1.943 & .055 \\
\hline & $\begin{array}{l}\text { portable } \\
\text { water }\end{array}$ & .031 & .003 & 11.164 & .000 \\
\hline & Population & $6.026 \mathrm{E}-05$ & .000 & 1.503 & .136 \\
\hline \multirow[t]{5}{*}{ NORTH (N) } & Constant & -37.671 & 33.681 & -1.118 & .266 \\
\hline & hand wash & -.873 & .872 & -1.001 & .319 \\
\hline & Hygiene & -4.549 & 2.325 & -1.957 & .053 \\
\hline & $\begin{array}{l}\text { portable } \\
\text { water }\end{array}$ & .031 & .003 & 11.258 & .000 \\
\hline & Population & .000 & .000 & 1.868 & .065 \\
\hline
\end{tabular}

Table 8: Correlation Matrix for senatorial districts comparison

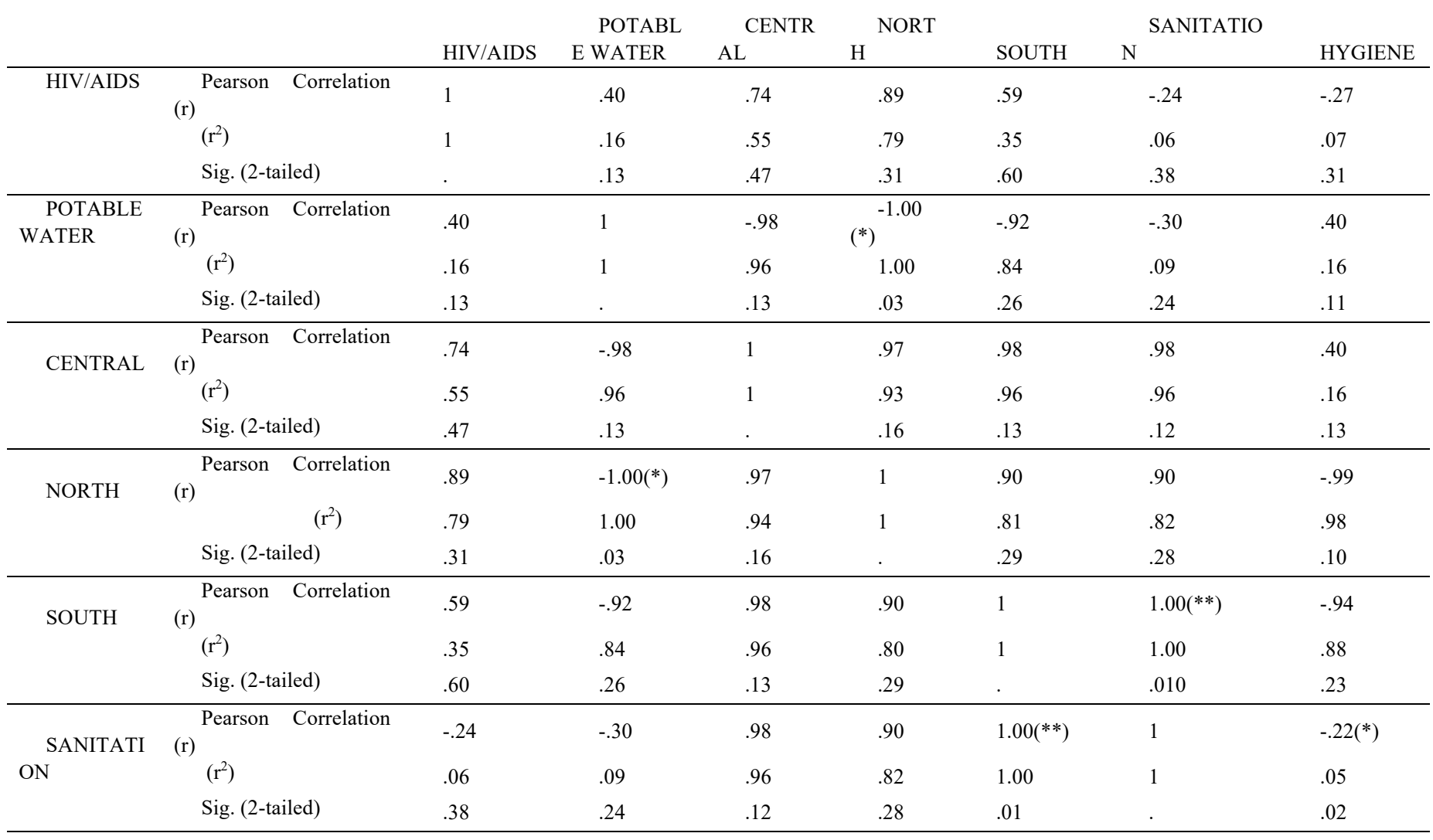




\begin{tabular}{|c|c|c|c|c|c|c|c|c|}
\hline \multirow{3}{*}{ HYGIENE } & $\begin{array}{ll} & \text { Pearson Correlation } \\
(\mathrm{r}) & \end{array}$ & -.27 & .40 & .40 & -.99 & -.94 & $-.22(*)$ & 1 \\
\hline & $\left(r^{2}\right)$ & .07 & .16 & .16 & .98 & .88 & .05 & 1 \\
\hline & Sig. (2-tailed) & .31 & .11 & .13 & .10 & .23 & .02 & . \\
\hline
\end{tabular}

** Correlation is significant at the 0.01 level (2-tailed). * Correlation is significant at the 0.05 level (2-tailed).

From the correlation matrix of Table 8, the following comparisons of variables were observed: HIV/AIDS and Potable water show that there was a low positive association of .40 between them. HIV/AIDS and Central indicate a high positive association that was about .74 of the population having HIV/AIDS, while HIV/AIDS and North show higher percentage of about $.89 \%$. HIV/AIDS and South also indicate a positive association of .59 between HIV/AIDS and Sanitation there was low negative association of -.24 which could be further said that HIV/AIDS did not have relationship with sanitation, so also there was a low negative association of -.27 between HIV/AIDS and Hygiene. The association between Potable water and Central, North and South showed high negative association of $-.98,-1.00$ and .92 respectively which means that majority of people in all the three senatorial districts did not have access to potable water. The association between Sanitation and Central, North and South indicated high positive association of .98, .90 and 1.00 respectively meaning that the levels of sanitation in the three senatorial districts are high. Whereas on association between Hygiene and the three senatorial districts, only the Central showed a low positive association of .40, while North and South showed high negative association of -.99 and -.94 respectively.

The availability of safe drinking water depends not only on the treatment adopted for water but also its storage. In some instances, water becomes contaminated in the course of storage and this makes it unsafe (Afolabi, 2008). In cities, increasing proportion of people have access to an improved source of drinking water. However, the rural areas suffer more in terms of acute shortages of water and the quality of the water is usually found to be poor. The practice of treating water is more popular for urban residents, but it is significantly low for those in rural areas who actually have less access to safe water.

\section{CONCLUSION}

This section presents the conclusion of this study based on findings and results of the research work. It was revealed that $3.62 \%$ of Ekiti citizen were supplied with potable water. The planning for infrastructure (water) in Ekiti State was clearly seen to be grossly low. No adequate planning for water supply has been done for a very long period of time by the government. It was revealed that three local governments i.e. Ise/Orun, Ekiti East and Emure, had not been supplied with potable water at all. Even Ado Local Government Area as the state capital was having just $8 \%$ of her population being served with potable water, while Ido/Osi local government which had the highest percentage of $11.94 \%$ can still be termed low. On the availability of potable water, and its contribution to the spread of HIV/AIDS in Ekiti State, the result of the analysis shows that $40 \%$ of the respondents sourced their water from well, $30 \%$ from pipe-borne water, $20 \%$ from borehole, while $0.9 \%$ got water from streams. It was also interesting to note that during the dry season, buying water was the major source of water to the respondents in Ekiti State (over 50\%), while $21 \%$ got water from other sources, such as boreholes during the dry season, while, $(14.5 \%)$ of the respondents got their water from the streams during dry seasons. This trend has a great implication for the spread of HIV/AIDS as it particularly found to presents opportunities for the exchange of water for sex among other sharp heterosexual and risky practices. Though, it has been shown that the relationship between water, sanitation, hygiene and HIV/AIDS could be secondary but it is apparently clear that the resultant of all these cannot be over-emphasized.

Hence the control, development, monitoring, evaluation and management of these relationships will definitely affect and influence the well-being of the PLWHA and their respective life because they cannot live in isolation of their environmental influence and factors. It is clear from the results of this research work that there are risks factors associated with potable water and incidence of HIV/AIDS in Ekiti State. According to the findings potable water supply reduces the risk of exchanging of sex for water and rape, and hence reducing the spread of HIV/AIDS. The results of the analysis indicates that sanitation and hygiene have negative relationships with HIV/AIDS, which implies that an increase in sanitation could lead to a reduction in the spread of HIV/AIDS. This study covered the area of the quantity of water needed by PLWHA, and it has been able to identify that pipe-borne water is not readily available for PLWHA. Also it was discovered that PLWHA got alternative sources of water supply through well, stream, spring etc., but the quality of these sources of water supply were not covered by this research therefore this aspect was left for further research. 


\section{REFERENCES}

[1] Bloomfield G.S, Khazanie P, Morris A, Rabadán-Diehl C, Benjamin L.A, Murdoch D, Hicks C (2014). HIV and non-communicable cardiovascular and pulmonary diseases in low-and middle-income countries in the ART era: what we know and best directions for future research. Journal of acquired immune deficiency syndromes (1999), 67(0 1), S40.

[2] Lule, J. R., Mermin, J., Ekwaru, J. P., Malamba, S., Downing, R., Ransom, R. \& Kaharuza, F. (2005). Effect of home-based water chlorination and safe storage on diarrhea among persons with human immunodeficiency virus in Uganda. The American journal of tropical medicine and hygiene, 73(5), 926-933.

[3] Mackinnon, E., Ayah, R., Taylor, R., Owor, M., Ssempebwa, J., Olago, L. D., \& Fottrell, E. (2019). 21st century research in urban WASH and health in sub-Saharan Africa: methods and outcomes in transition. International journal of environmental health research, 29(4), 457-478.

[4] Ekiti State Action Committee on AIDS (2009) Ekiti State HIV/AIDS Response Review 2004-2008. Ado Ekiti, EKSACA.

[5] Keating, J., Meekers, D., \& Adewuyi, A. (2006). Assessing effects of a media campaign on HIV/AIDS awareness and prevention in Nigeria: results from the VISION Project. BMC Public health, 6(1), 123.

[6] Loucks, D. P., \& Van Beek, E. (2017). Water resource systems planning and management: An introduction to methods, models, and applications. Springer.

[7] Falkenmark, M., Rockstrom, J., \& Rockström, J. (2004). Balancing water for humans and nature: the new approach in ecohydrology. Earthscan.

[8] UNICEF. (2007). The state of the world's children 2008: Child survival (Vol. 8). UNICEF.

[9] Ucha, C. (2010). Poverty in Nigeria: Some dimensions and contributing factors. Global Majority E-Journal, 1(1), 46-56.

[10] Hutton, G., Haller, L., Water, S., \& World Health Organization. (2004). Evaluation of the costs and benefits of water and sanitation improvements at the global level (No. WHO/SDE/WSH/04.04). Geneva: World Health Organization.

[11] Hubbard, B., Sarisky, J., Gelting, R., Baffigo, V., Seminario, R., \& Centurion, C. (2011). A community demand-driven approach toward sustainable water and sanitation infrastructure development. International journal of hygiene and environmental health, 214(4), 326-334.

\section{AUTHORS-DETAILS}

Folorunso Owoola

Federal Teaching Hospital, Ido-Ekiti, Ekiti-State, Nigeria. Email: owoolafolorunso@gmail.com

Wole W. Adebayo

Department of Geography and Planning Science, Ekiti State University, Ado-Ekiti, Nigeria.

Email: wole.adebayo@yahoo.com

Kayode O. Olowe* (Corresponding author) Civil Engineering Department, Afe-Babalola University, Ado-Ekiti, Nigeria. Email: owenkaay2001@yahoo.com 